
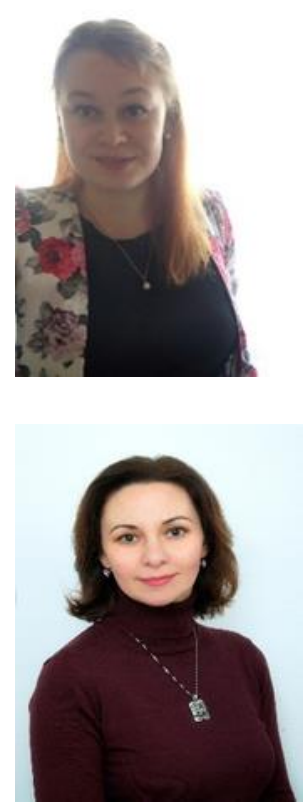

\section{ИСПОЛЬЗОВАНИЕ БИОЛОГИЧЕСКИХ ПРЕПАРАТОВ ДЛЯ ПОВЫШЕНИЯ ПОСЕВНЫХ КАЧЕСТВ СЕМЯН АСТРАГАЛА МОНГОЛЬСКОГО (ASTRAGALUS MONGHOLICUS BGE.)}

\author{
Н.С. Болтова, студент кафедры агрономии \\ e-mail: nadya.boltova@mail.ru \\ ФГБОУ ВО «Калининградский государственный \\ технический университет»
}
Е.А. Калинина, канд. биол. наук, доцент кафедры агрономии e-mail: ekaterina.kalinina@klgtu.ru
ФГБОУ ВО «Калининградский государственный технический университет»

В статье представлены результаты исследования оценки эффективности биологических препаратов при повышении посевных качеств семян астрагала монгольского. Установлено, что изученные препараты Рибав-Экстра и Восток ЭМ-1 (ЭМ-био) в различных концентрациях положительно влияют на прорастание и всхожестьсемян. При этом действие препарата Восток ЭМ-1 в концентрации 2 мл/л воды оказалось несколько сильнее, чем действие этого же препарата в концентрации 1 мл/л воды. Эффективность действие Рибав-Экстра в концентрации 0,2 мл/л воды было больше, чем в концентрации 0,1 мл/л воды. При сравнении двух эффективно действующих препаратов, более эффективным оказался ЭМ-био (Восток ЭМ-1) в концентрации 2 мл/л воды - всхожесть в этом варианте составила $68 \%$. Исследования, направленные на повышение посевных качеств семян, являются важным элементом в технологии возделывания лекарственных растений.

\footnotetext{
Ключевые слова: астрагал монгольский, всхожесть, энергия прорастания, биологические препаратьл
}

\title{
ВВЕДЕНИЕ
}

При культивировании лекарственных растений важным этапом является подготовка семян к посеву, которая обеспечивает равномерные всходы и полноценный урожай. Повышение посевных качеств семян - важная задачадля оптимизации технологии возделывания лекарственных растений в условиях Калининградской области.

Для стимулирования прорастания семян применяют различные методы. В работе для повышения всхожести и энергии прорастания семян астрагала монгольского применены биологические препараты Рибав-Экстра и Восток ЭМ-1 (ЭМ-био препарат).

Исследовательская работа выполнена в рамках научной тематики и плана проведения инициативных научно-исследовательских работ 10.14.010.2: «Молекулярно-биологические механизмы взаимодействия живых организмов с окружающей средой как фундаментальная основа прикладной биологии и сельского хозяйства» кафедры агрономии ФГБОУ ВО «Калининградский государственный технический университет». 


\section{ОБЪЕКТ ИССЛЕДОВАНИЯ}

Объектом исследований явился Астрагал монгольский (Astragalus mongholicus Bunge.)вид, относящийся к крупному роду Astragalus в семействе Fabaceae, входит в состав флоры сосудистых растений Монголии. Астрагал монгольский является ценным перспективным лекарственным растением, применяемым при многих заболеваниях в медицинской практике [1].

\section{ЦЕЛЬ И ЗАДАЧИ ИССЛЕДОВАНИЯ}

Цель исследования: изучение влияния биопрепаратов на посевные качества семян астрагала монгольского.

Задачи исследования:

- изучить влияние биопрепарата Рибав-Экстра в концентрациях 0,1 и 0,2 мл/л воды на всхожесть и энергию прорастания семян астрагал монгольского;

- изучить влияние биопрепарата Восток ЭМ-1 в концентрациях 1 и 2 мл/л воды на всхожестьи энергию прорастания семян астрагал монгольского.

\section{МЕТОДЫ ИССЛЕДОВАНИЯ}

Исследование проводили в осенний период 2020 г. в лабораторных условиях.

Для стимулирования прорастания и улучшения посевных качеств семян использовали биологические препараты:

- Рибав-Экстра, д.в. 0,00152 г/л L-аланина + 0,00196 г/л L-глутаминовой кислоты. ПроизводительАО Фирма «АВГУСТ». Применяется для повышения энергии прорастания, стимулирования корнеобразования, всхожести, ранней общей урожайности и устойчивости к заболеваниям [2].

- Восток ЭМ-1. ЭМ-биоили ЭМ-препарат - это микробиологический препарат, содержащий эффективные микроорганизмы: молочнокислые, фотосинтезирующие, азотфиксирующие бактерии, дрожжи и продукты их жизнедеятельности. Эффективность действия заключается в повышении урожайности, содержания витаминов в плодах, восстановлении естественного плодородия почв, снижении содержания нитратов в плодах [3].

Определяли всхожесть и энергию прорастания семян астрагала монгольского в соответствии с ГОСТ 12038-84 [4].

Предварительно семена стратифицировали вручную наждачной бумагой путем счищения верхнего слоя эпидермиса семени. Далее семена помещались в чашки Петри на фильтровальную бумагу и обрабатывались препаратами в концентрациях, рекомендованных производителем и увеличенных вдвое по сравнению с рекомендованными. Препараты растворяли в дистиллированной воде.

Опыт проведен в четырех повторениях с повторностью равной 100. Результаты обработаны статистически, в таблицах представлены средние арифметические значения и их стандартные отклонения. Схема опыта представлена на рис.

\section{РЕЗУЛЬТАТЫ ИССЛЕДОВАНИЯ}

Как показали результаты исследования (табл. 1 и 2), препараты Рибав-Экстра и Восток ЭМ-1 в целом положительно повлияли на посевные качества семян астрагала монгольского, увеличивая их всхожесть и энергию прорастания.

Энергия прорастания семян в варианте Рибав-Экстра в концентрациях 0,1 мл/ л воды была больше контрольного соответственно на 4 \%, а в концентрации 0,2 мл/л воды - на $7 \%$.

Более существенные различия наблюдались в варианте с препаратом Восток ЭМ-1. Энергия прорастания составила на 10 \% больше контроля в варианте с концентрацией 1 мл/л воды и $13 \%$ в варианте 2 мл/л воды. 


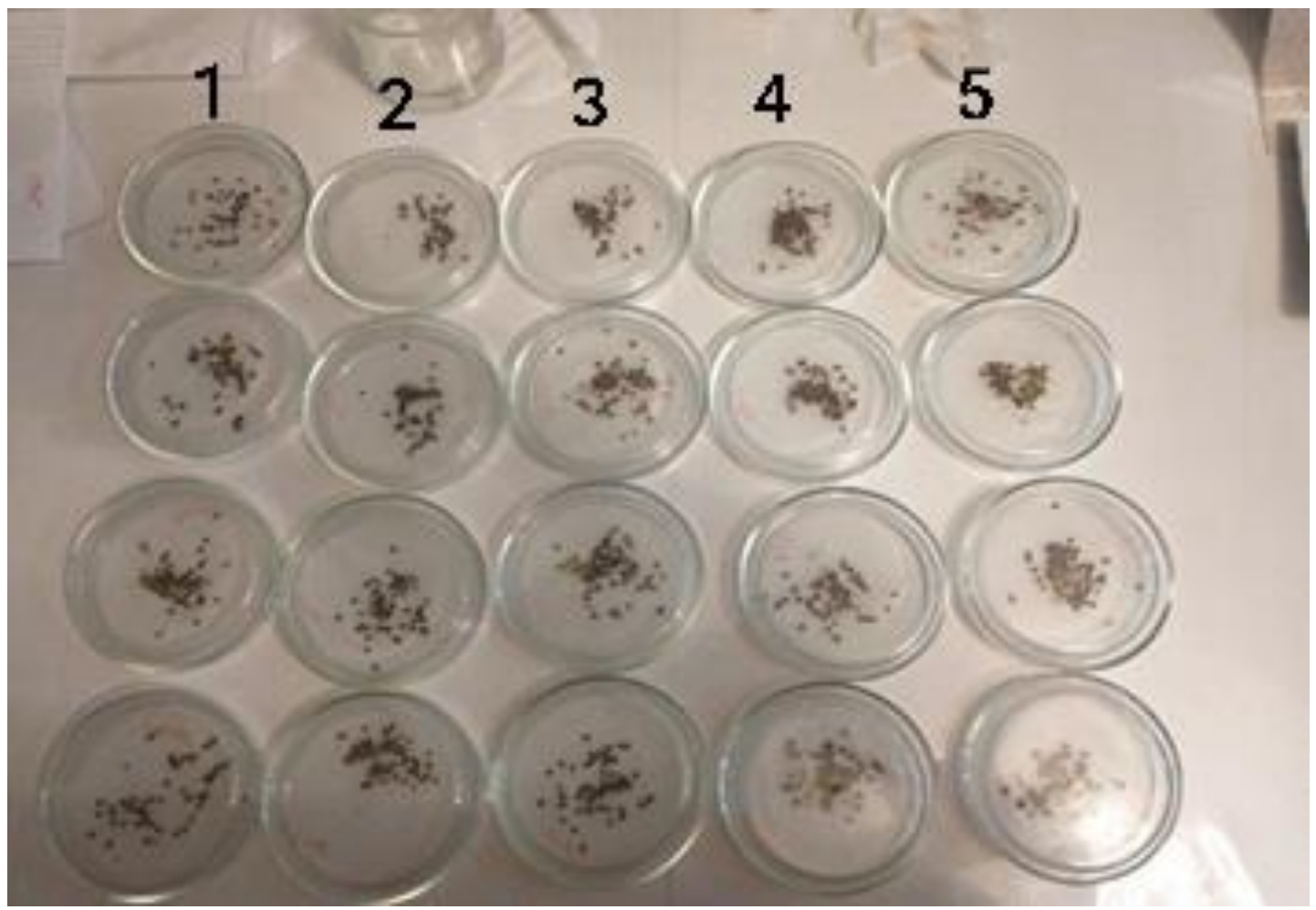

Рисунок - Варианты опыта по определению всхожести и энергии прорастания семян астрагала монгольского:

1 - Рибав-Экстра (0,1 мл/1 л воды); 2 - Рибав-Экстра (0,2 мл/1 л воды);

3 - Восток ЭМ-1 (1 мл/1л воды); 4 - Восток ЭМ-1(2 мл/1л воды);

5 - дистиллированная вода

Таблица 1 - Энергия прорастания семян астрагала монгольского, \%

\begin{tabular}{|c|c|c|c|c|}
\hline \multicolumn{4}{|c|}{ Варианты опыта } \\
\hline \multirow{2}{*}{$\begin{array}{c}\text { Контроль } \\
\text { (без обработки) }\end{array}$} & \multicolumn{2}{|c|}{ Рибав-Экстра } & \multicolumn{2}{c|}{ Восток ЭМ-1 } \\
\cline { 2 - 5 } & 0,1 мл/л воды & 0,2 мл/ л воды & 1 мл/л воды & 2 мл/л воды \\
\hline $52 \pm 5,0$ & $56 \pm 6,0$ & $59 \pm 4,0$ & $62 \pm 4,0$ & $65 \pm 6,0$ \\
\hline
\end{tabular}

Таблица 2 -Всхожесть семян астрагала монгольского, \%

\begin{tabular}{|c|c|c|c|c|}
\hline & \multicolumn{2}{|c|}{ Варианты опыта } \\
\hline Контроль & \multicolumn{2}{|c|}{ Рибав-Экстра } & \multicolumn{2}{c|}{ Восток ЭМ-1 } \\
\cline { 2 - 5 } (без обработки $)$ & 0,1 мл/л воды & 0,2 мл/ л воды & 1 мл/л воды & 2 мл/л воды \\
\hline $57 \pm 3,0$ & $60 \pm 4,0$ & $62 \pm 3,0$ & $64 \pm 5,0$ & $68 \pm 4,0$ \\
\hline
\end{tabular}

Биопрепараты повышали всхожесть семян астрагала монгольского. В варианте с Рибав-Экстра (0,2 мл/л воды) всхожесть семян увеличилась на $5 \%$ по сравнению с контрольным, но была ниже по сравнению с вариантом Восток ЭМ-1 в обеих концентрациях. Эффективность действия Рибав-Экстра в концентрации 0,2 мл/л воды была больше, чем в концентрации 0,1 мл/л воды.

При этом действие препарата Восток ЭМ-1 в концентрации 2 мл/л воды оказалось несколько сильнее, чем действие этого же препарата в концентрации 1 мл/л воды, статистически достоверно увеличение всхожести отмечалось в сравнении с контрольным вариантом на $11 \%$.

Стоит также отметить, что при сравнении двух эффективно действующих препаратов, более эффективным оказался Восток ЭМ-1 в концентрации 2 мл/л воды - всхожесть в этом варианте составила $6 \%$. 
Проводимые исследования необходимы для разработки биологических систем производства качественного посевного материала лекарственных растений, адаптированных к почвенно-климатическим условиям района культивирования.

\title{
ВЫВОДЫ
}

Полученные результаты позволили сделать следующие выводы:

1. Выявлено положительное действие биопрепаратов на всхожесть и энергию прорастания семян астрагала монгольского.

2. Препарат Рибав-Экстра в концентрации 0,2 мл/л повысил всхожесть стратифицированных семян астрагал монгольского в сравнении с Рибав-Экстра в концентрации 0,1 мл/л воды на $2 \%$, с контролем - $5 \%$.

3. Препарат Восток ЭМ-1 в концентрации 2 мл/л воды оказался более эффективным по сравнению с контролем и Рибав-Экстра; всхожесть семян астрагала монгольского увеличилась на 11 \% посравнению с контролем и на 6 \% по сравнению с Рибав-экстра $(0,2$ мл/л воды).

\section{СПИСОК ЛИТЕРАТУРЫ}

1. Алексеева, Е.В. Некоторые особенности экологической адаптации и морфогенеза Astragalus mongholicus Bunge / Е.В. Алексеева // Биологические науки / под ред. Л.Б. Буянтуева // Вестник Бурятского государственного университета.- 2010. - С. 44-46.

2. Рибав-Экстра, Р [Электронный ресурс]. - Режим доступа: https://www.agroxxi.ru/goshandbook/prep/ribav-ekstra-p-2.html (дата обращения: 05.02.2021г.).

3. Чачина, С.Б. Биологическая рекультивация нефтезагрязненных почв с использованием микробиологических препаратов «Байкал-ЭМ», «Тамир», «Восток» / С.Б. Чачина, С.В. Болтунова // Международный журнал прикладных и фундаментальных исследований. - 2015. - № 11-2. - С. 274-276.

4. ГОСТ 12038-84-2011. Семена сельскохозяйственных культур. Методы определения всхожести. - Москва, 2011. - 64 с.

\section{USE OF BIOLOGICAL RESOURCES PREPARATIONS FOR IMPROVING THE SOWING QUALITIES OF SEEDS ASTRAGALUS OF MONGOLIA (ASTRAGALUS MONGHOLICUS BGE.)}

\author{
N.S. Boltova, student \\ e-mail: nadya.boltova@mail.ru \\ Kaliningrad State Technical University
E.A. Kalinina, Candidate of Biological Sciences
e-mail: ekaterina.kalinina@klgtu.ru
Kaliningrad State Technical University

The article presents the results of a study to evaluate the effectiveness of biological preparations in improving the sowing qualities of Mongolian astragalus seeds. It was found that the studied preparations Ribav-Extra and Vostok EM-1 (EM-bio) in different concentrations positively affect the germination and germination of seeds. At the same time, the effect of the drug Vostok EM-1 at a concentration of $2 \mathrm{ml} / 11$ of water was slightly stronger than the effect of the same drug at a concentration of $1 \mathrm{ml} / 1 \mathrm{l}$ of water. The effect of Ribav-Extra at a concentration of $0.2 \mathrm{ml} / 11$ of water was greater than at a concentration of $0.1 \mathrm{ml} / 1 \mathrm{~L}$ of water. When comparing two effective drugs, EM-bio (Vostok EM-1) was more effective at a concentration of $2 \mathrm{ml} / 1 \mathrm{l}$ of water - the 
germination rate in this variant was $68 \%$. Research aimed at improving the sowing qualities of seeds is an important element in the technology of cultivation of medicinal plants.

Key words: astragalus Mongolian, energy germination, biological preparations 